\title{
A Case of Type I Hepatorenal Syndrome Treated with Vasopressin
}

\author{
Laura Connor ${ }^{1}$, Geoffrey Teehan ${ }^{2,3}$ \\ ${ }^{1}$ Department of Internal Medicine, Lankenau Medical Center, Wynnewood, USA \\ ${ }^{2}$ Department of Nephrology, Lankenau Medical Center, Wynnewood, USA \\ ${ }^{3}$ Lankenau Institute of Medical Research, Wynnewood, USA \\ Email: connorl@mlhs.org
}

Received July 3, 2013; revised August 2, 2013; accepted August 13, 2013

Copyright (c) 2013 Laura Connor, Geoffrey Teehan. This is an open access article distributed under the Creative Commons Attribution License, which permits unrestricted use, distribution, and reproduction in any medium, provided the original work is properly cited.

\begin{abstract}
Hepatorenal syndrome (HRS) is a grave complication of end-stage liver disease and is associated with a very high mortality. This case report described a 42-year-old female with advanced alcohol-induced cirrhosis who developed HRS that was initially treated with Midodrine and Octreotide but renal function continued to deteriorate. Vasopressin therapy was added and HRS was successfully reversed. There are few data available on the use of vasopressin for HRS and this case supports its use in treatment of HRS, particularly in countries where the more widely studied Terlipressin is unavailable. This case also demonstrates that a patient failing one medical therapy for HRS may respond to an alternative or adjunctive therapy. Therefore, this should be attempted to increase the patient's chance of survival.
\end{abstract}

Keywords: Hepatorenal Syndrome; Vasopressin

\section{Introduction}

Hepatorenal syndrome (HRS) is a grave complication of end-stage liver disease and is associated with a very high mortality. It is characterized by arterial vasodilation of the splanchnic vessels leading to pronounced renal vasoconstriction, marked reduction in renal blood flow and glomerular filtration rate [1]. HRS is classified into two types based on the rate of progression of the renal dysfunction. Type 1 is characterized by an abrupt onset and a rapid progression of renal failure over a period of two weeks or less with a median survival of one to two weeks. Type 2 causes a more slowly progressive renal failure, typically over months with a median survival of about six months [2]. Management of HRS is challenging since the ideal treatment is liver transplantation, which is usually difficult to accomplish in a short timeframe. Therefore, patients with HRS are typically managed medically with the goal to improve renal function and survival as a bridge to transplantation. In Europe, the Vasopressin analogue Terlipressin, has been used successfully. Unfortunately, this medication is costly and not available in many countries, including North America [1]. Here, we present a case of Type 1 Hepatorenal Syndrome that is successfully reversed with vasopressin.

\section{Case Report}

A 43-year-old female with no significant past medical history presented to the emergency department complaining of bilateral lower extremity edema, abdominal pain, nausea, and vomiting that had progressively worsened over the past month. Review of systems was positive for jaundice, increased abdominal girth, fevers, and occasional hematochezia and hematemesis. She had been taking three to four grams of Acetaminophen daily for the past three months for rib pain, and been consuming two to three alcoholic drinks per day, three to four times a week. She was admitted to the hospital February 2011 for investigation of her symptoms.

The workup disclosed probable alcohol-induced cirrhosis compounded by concomitant use of acetaminophen. On hospital day 9, the patient's urine output declined to $14 \mathrm{cc} / \mathrm{hr}$ and urine sodium was low ( $<10 \mathrm{meq} / \mathrm{l})$ suggesting Hepatorenal Syndrome despite a stable creatinine. She was treated with Octreotide and Midodrine for 5 days while the serum creatinine remained stable. On hospital day 18, the patient developed acute kidney injury with creatinine increasing from $1.0 \mathrm{mg} / \mathrm{dl}$ to 1.3 $\mathrm{mg} / \mathrm{dl}$. The etiology was either pre-renal from increasing diuretics versus hepatorenal syndrome. Urine sodium 
was low ( $<10 \mathrm{meq} / \mathrm{l})$, however serum creatinine improved with holding diuretics and giving an intravenous fluid challenge. Creatinine returned to baseline and diuretics were resumed on hospital day 21. On hospital day 23, urine output decreased to $23 \mathrm{cc} / \mathrm{hr}$ despite diuretics so Octreotide and Midodrine were again initiated for treatment of possible HRS. By hospital day 25, creatinine rose to $1.2 \mathrm{mg} / \mathrm{dl}$ and the patient continued to be diuretic resistant. Urine sodium was found to be $87 \mathrm{meq} / \mathrm{l}$ in the setting of diuretic use. The following day creatinine was $1.3 \mathrm{mg} / \mathrm{dl}$, diuretics were discontinued and urine sodium was $<10 \mathrm{meq} / \mathrm{l}$ consistent with hepatorenal syndrome. Octreotide, midodrine and albumin were continued. Despite being on this therapy for eleven days, creatinine continued to rise from $1.0 \mathrm{mg} / \mathrm{dl}$ to $3.6 \mathrm{mg} / \mathrm{dl}$ during this time period. There were no obvious nephrotoxic exposures, episodes of low blood pressure, nor any evidence of urinary retention.

Failing Octreotide and Midodrine therapy and being an unsuitable candidate for liver transplantation due to alcohol use, on hospital day 33, she was transferred to the intensive care unit to begin Vasopressin infusion. Octreotide, Midodrine and albumin were continued as ongoing adjunctive therapy. Vasopressin was initially administered at 0.02 units $/ \mathrm{min}$. The following morning creatinine rose from $3.6 \mathrm{mg} / \mathrm{dl}$ to $3.8 \mathrm{mg} / \mathrm{dl}$ and vasopressin was increased to 0.04 units $/ \mathrm{min}$. After approximately 48 to 72 hours of vasopressin infusion, serum creatinine began to trend down. Vasopressin therapy was continued for 12 days until creatinine was $1.2 \mathrm{mg} / \mathrm{dl}$, near baseline of $0.8 \mathrm{mg} / \mathrm{dl}$. Vasopression dose was decreased by $50 \%$ for one day, then removed completely. Creatinine remained stable after being off vasopressin for 48 hours at which point Octreotide and Midodrine were discontinued. Creatinine continued to remain stable and was $1.1 \mathrm{mg} / \mathrm{dl}$ at the time of discharge. At two and ten weeks post-hospital discharge, creatinine had returned and re- mained stable at baseline of $0.8 \mathrm{mg} / \mathrm{dl}$.

During treatment with Vasopressin, no improvement in liver function tests or coagulation factors occurred. Child-Pugh score was 10 before and after treatment with vasopressin. MELD score decreased from 33 to 21 from beginning to end of treatment owing to the decrease in serum creatinine achieved.

In summary, a 43-year-old female who presented with bilateral lower extremity edema, abdominal pain and increased girth, nausea and vomiting was found to have end-stage liver disease secondary to alcohol. During her hospitalization she developed type 1 hepatorenal syndrome. Initially she was treated with Midodrine, Octreotide and albumin but renal function continued to decline. Vasopressin was added and her renal function recovered to baseline.

\section{Discussion}

The only definitive therapy to reverse renal failure in hepatorenal syndrome is successful liver transplantation. HRS carries a very poor prognosis with high mortality rate, which makes liver transplantation often not possible before the disease is fatal [3]. There are several pharmacologic therapies that have been shown to improve renal function in patients with HRS. These treatments can be used to improve survival until a transplant is possible.

Data suggests that the combination of Midodrine, a selective $\alpha-1$ adrenergic agonist and systemic vasoconstrictor, and Octreotide, a somatostatin analog and inhibitor of endogenous vasodialators, to be effective in prolonging survival in HRS [4,5]. One study using Octreotide alone did prove to be effective in the treatment of HRS [6]. Results of these studies are summarized in Table 1 [4-6]. A benefit to using the combination of oral Midodrine and subcutaneous Octerotide is the ability to use this therapy in the outpatient setting [3]. In this presented case, however, treatment with Midodrine,

Table 1. Summary of studies involving midodrine and octreotide for treatment of HRS.

\begin{tabular}{|c|c|c|c|c|}
\hline Author & Study Design & Participants & Treatment & Outcomes \\
\hline Angeli [4] & $\begin{array}{l}\text { Prospective, } \\
\text { single center }\end{array}$ & $\begin{array}{l}13 \text { patients with } \\
\text { type } 1 \mathrm{HRS}\end{array}$ & $\begin{array}{l}\text { Midodrine + octreotide } \\
\text { + albumin vs } \\
\text { dopamine + albumin }\end{array}$ & $\begin{array}{c}\text { Midodrine and octreotide in combination } \\
\text { with intravenous albumin lowered serum } \\
\text { creatinine, increased GFR, and increased } \\
\text { urine volume in } 5 \text { of } 5 \text { patients compared } \\
\text { to } 1 \text { of } 8 \text { patients treated with dopamine } \\
\text { and albumin. }\end{array}$ \\
\hline Esrailian [5] & $\begin{array}{l}\text { Retrospective, } \\
\text { single center }\end{array}$ & $\begin{array}{l}81 \text { patients with } \\
\text { type } 1 \text { HRS }\end{array}$ & $\begin{array}{l}\text { Midodrine }+ \text { octreotid } \\
\text { vs untreated controls }\end{array}$ & $\begin{array}{l}40 \% \text { of patients treated with midodrine } \\
\text { and octreotide had sustained reduction in } \\
\text { serum creatinine compared to } 10 \% \text { in } \\
\text { untreated controls. } 30 \text {-day survival was } \\
57 \% \text { in treated patients compared to } 29 \% \\
\text { in untreated controls. }\end{array}$ \\
\hline $\begin{array}{l}\text { Pomier-Layragues } \\
{[6]}\end{array}$ & $\begin{array}{l}\text { Prospective, } \\
\text { randomized, } \\
\text { double-blind, } \\
\text { cross-over, single } \\
\text { center }\end{array}$ & $\begin{array}{c}19 \text { patient with } \\
\text { type } 1 \text { or type } 2 \\
\text { HRS }\end{array}$ & $\begin{array}{l}\text { Octreotide + albumin vs } \\
\text { placebo }+ \text { albumin }\end{array}$ & $\begin{array}{l}\text { Octreotide did not prove to be } \\
\text { effective in the treatment of HRS }\end{array}$ \\
\hline
\end{tabular}


Octreotide, and albumin did not reverse HRS and renal function continued to deteriorate on therapy. Our patient was not a candidate for a liver transplant causing us to search for another treatment alternative.

Many studies have shown promising results using vasopressin analogs (Terlipressin and Ornipressin) particularly for prolonging survival in the rapidly fatal type 1 HRS. Vasoconstriction of the splanchnic vascular bed is believed to be responsible for the reversal of HRS by ultimately decreasing compensatory renal vasoconstric- tion and increasing renal perfusion [3]. Terlipressin and Ornipressin are unavailable in many countries, including the United States. Although Terlipressin has been more widely studied, the wide availability of Vasopression in countries where Terlipressin is unavailable has led to its use in treatment of HRS. A summary of studies using Vasopressin and its analogs can be found in Table 2 [7-18].

Little data exists on Vasopressin for HRS and this case further supports its use in treatment of HRS. Specifically in this case, Vasopressin, in conjunction with Midodrine,

Table 2. Summary of studies involving vasopressin and vasopressin analogs in treatment of HRS.

\begin{tabular}{cccc}
\hline Author & Study Design & Participants & Treatment \\
\hline Moreau [7] & $\begin{array}{c}\text { Retrospective, } \\
\text { multicenter }\end{array}$ & $\begin{array}{c}\text { 99 patients with type I } \\
\text { HRS }\end{array}$ & Terlipressin \\
Halimi [8] & $\begin{array}{c}\text { Retrospective, } \\
\text { multicenter }\end{array}$ & $\begin{array}{c}\text { 19 patients with type 1 } \\
\text { HRS; 2 patients with } \\
\text { Type 2 HRS }\end{array}$ & Terlipressin \\
& $\begin{array}{c}\text { Prospective, randomized, } \\
\text { double-blind, } \\
\text { Slacebo-controlled, } \\
\text { multicenter }\end{array}$ & 56 patients with type 1 & Terlipressin vs placebo \\
& HRS albumin
\end{tabular}

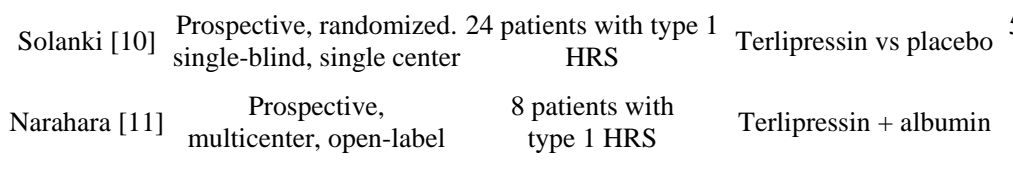

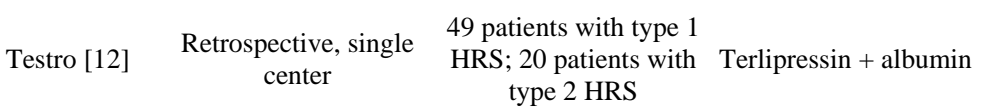

Neri [13] Prospective, randomized, 52 patients with type 1 Terlipressin + albumin multicenter HRS vs albumin

Martin-Llahi Prospective, randomized, 35 patients with type 1 [14] multicenter HRS; 11 patients with type 2 HRS

Terlipressin + albumin vs albumin
.

Prospective,

Ortega [15] observational, single center
16 patients with type 1 HRS; 5 patients with type 2 HRS Terlipressin + albumin
vs terlipressin

\section{Outcomes}

$64 \%$ of patients had improved renal

function. Survival rate was $40 \%$ at 1 month.

$72 \%$ of patients had improved renal function. Long term survival was achieved in two patients.

HRS reversal was achieved in 34\% treated with Terlipressin versus $13 \%$ treated with placebo plus albumin. Reversal of HRS significantly improved survival at 180 days

5 of 12 patients treated with Terlipressin survived to day 15 versus 0 of 12 patients in the placebo group

$75 \%$ of patients had a complete response $(\mathrm{Cr} \leq 1.5 \mathrm{mg} / \mathrm{dl})$ to treatment. Median survival was 35 days.

37 of 49 (77.5\%) patients with Type 1 HRS and 4 of 20 (20\%) patients with Type 2 HRS responded to treatment. 17 of 49 (35\%) patients with Type 1 HRS and 4 of 20 (20\%) patients with Type 2 HRS achieved long-term survival.

$80 \%$ of patients treated with Terlipressin plus albumin demonstrated a complete response $(\mathrm{Cr} \leq 1.5 \mathrm{mg} / \mathrm{dl})$ compared to $19 \%$ of patients treated with albumin alone. Reversal of HRS was strongly associated with improved survival.

Terlipressin plus albumin improved renal function compared to albumin alone (45\% vs $8.7 \%$ ). No significant different in 3-month survival between terlipressin plus albumin vs albumin montherapy (27\% vs $19 \%)$.

A complete response was seen in $77 \%$ of patients receiving terlipressin plus albumin compared to $25 \%$ of patients treated with terlipressin alone. Occurrence of complete response was associated with an improved survival.
Prospective,

Guevera [16] nonrandomized, single center

Prospective,

Gulberg [17] nonrandomized, single $\begin{gathered}7 \text { patients with type } 1 \\ \text { HRS }\end{gathered}$ Ornipressin + dopamine center

16 patient with HRS

(Type not specified)

Ornipressin + albumin

Ornipression plus albumin was successful at reversing HRS with 15 days of treatment. Three patients developed ischemic complications.
HRS reverted in 4 of 7 patients treated with ornipressin plus dopamine. 3 of 7 survived to transplantation.

Complete response occurred in $42 \%$ of patients treated with vasopressin plus octreotide, $38 \%$ of patients treated with vasopressin alone and $0 \%$ of patients treated with octreotide alone. Survival was improved in patients treated with vasopressin and they were more likely to receive a liver transplant 
Octreotide and albumin successfully reversed HRS. This case also demonstrates that a patient failing one medical therapy for HRS may respond to an alternative or adjunctive therapy; therefore these methods should be attempted to increase the patient's chance of survival.

\section{Conclusion}

In conclusion, we have reported a case of type 1 HRS that is successfully treated with vasopressin. There are studies in Europe using terlipressin that have shown some success, however, terlipressin is not available in many countries. Since terlipressin is not available in the United States, vasopressin is used as an alternative and is successful in this reported case. We would advocate the use of vasopressin where terlipressin is unavailable, particularly when other available treatments are failing to reverse renal failure.

\section{REFERENCES}

[1] C. Alessandria, A. Ottobrelli, W. Debernardi-Venon, L. Todros, M. T. Cerenzia, S. Martini, et al., "Noradrenalin vs Terlipressin in Patients with Hepatorenal Syndrome: A Prospective, Randomized, Unblinded, Pilot Study,” Journal of Hepatology, Vol. 47, No. 4, 2007, pp. 499-505. doi:10.1016/j.jhep.2007.04.010

[2] S. J. Munozo, “The Hepatorenal Syndrome," Medical Clinics of North America, Vol. 92, No. 4, 2008, pp. 813-837. doi:10.1016/j.mcna.2008.03.007

[3] T. H. Kiser, R. Maclaren and D. N. Fish, "Treatment of Hepatorenal Syndrome,” Pharmacotherapy, Vol. 29, No. 10, 2009, pp. 1196-1211. doi:10.1592/phco.29.10.1196

[4] P. Angeli, R. Volpin, G. Gerunda, R. Craighero, P. Roner, R. Merenda, et al., "Reversal of Type 1 Hepatorenal Syndrome with the Administration of Midodrine and Octreotide," Hepatology, Vol. 29, No. 6, 1999, pp. 1690-1697. doi:10.1002/hep.510290629

[5] E. Esrailian, E. R. Pantangco, N. L Kyulo, K. Q. Hu and B. A. Runyon, "Octreotide/Midodrine Therapy Significantly Improves Renal Function and 30-Day Survival in Patients with Type 1 Hepatorenal Syndrome,” Digestive Diseases and Sciences, Vol. 52, No. 3, 2007, pp. 742-748. doi:10.1007/s10620-006-9312-0

[6] G. Pomier-Layragues, S. C. Paquin, Z. Hassoun, M. Lafortune and A. Tran, "Octreotide in Hepatorenal Syndrome: A Ransomized Double-Blind, Placebo-Controlled, Corssover Study,” Hepatology, Vol. 38, No. 1, 2003, pp. 238-243. doi:10.1053/jhep.2003.50276

[7] R. Moreau, F. Durand, T. Poynard, C. Duhamel, J. P. Cervoni, P. Ichai, et al., "Terlipressin in Patients with Cirrhosis and Type 1 Hepatorenal Syndrome: A Retroepsctive Mulitcenter Study,” Gastroenterology, Vol. 122, No. 4, 2002, pp. 923-930. doi:10.1053/gast.2002.32364

[8] C. Halimi, P. Bonnard, D. Bernard, P. Mathurin, A. Mofredj, V. Martino, et al., "Effect of Terlipressin (Glypressin) on Hepatorenal Syndrome in Cirrhotic Patients: Results of a Multicentre Pilot Study,” European Journal of Gastroenterology \& Hepatology, Vol. 14, No. 2, 2002, pp. 153-158. doi:10.1097/00042737-200202000-00009

[9] A. J. Sanyal, T. Boyer, G. Garcia-Tsao, F. Regenstein, L. Rossaro, B. Appenrodt, et al., "A Randomized, Prospective, Double-Blind, Placebo-Controlled, Trial of Terlipressin for Type 1 Hepatorenal Syndrome," Gastroenterology, Vol. 143, No. 5, 2008, pp. 1360-1368. doi:10.1053/j.gastro.2008.02.014

[10] P. Solanki, A. Chawla, R. Garg, R. Gupta, M. Jain and S. K. Sarin, "Beneficial Effects of Terlipressin in Hepatorenal Syndrome: A Prospective, Randomized PlaceboControlled Clinical Trial," Journal of Gastroenterology Hepatology, Vol. 18, No. 2, 2003, pp. 152-156. doi:10.1046/j.1440-1746.2003.02934.X

[11] Y. Narahara, H. Kanazawa, C. Sakamoto, H. Maruyama, O. Yokosuka, S. Mochida, et al., "The Efficacy and Safety of Terlipressin and Albumin in Patients with Type 1 Hepatorenal Syndrome: A Multicenter, Open-Label, Explorative Study," Journal of Gastroenterology, Vol. 47, No. 3, 2011, pp. 313-320. doi:10.1007/s00535-011-0485-8

[12] A. G. Testro, S. Wongseelashote, P. W. Angus and P. J. Gow, "Long-Term Outcome of Patients Treated with Terlipressin for Types 1 and 2 Hepatorenal Syndrome,” Journal of Gastroenterology and Hepatology, Vol. 23, No. 10, 2008, pp. 1535-1540. doi:10.1111/j.1440-1746.2007.05176.x

[13] S. Neri, D. Pulvirenti, M. Malaguarnera, B. M. Cosimo, G. Bertino, L. Ignaccolo, et al., "Terlipressin and Albumin in Patients with Cirrhosis and Type I Hepatorenal Syndrome,” Digestive Diseases and Sciences, Vol. 53, No. 3, 2008, pp. 830-835. doi:10.1007/s10620-007-9919-9

[14] M. Martin-Llahi, M. N. Pepin, M. Guevara, F. Diaz, A. Torre, A. Monescillo, et al., "Terlipressin and Albumine vs. Albumin in Patients with Cirrhosis and Hepatorenal Syndrome: A Randomized Study," Gastroenterology, Vol. 134, No. 5, 2008, pp. 1353-1359. doi:10.1053/j.gastro.2008.02.024

[15] R. Ortega, P. Gines, J. Uriz, A. Cardenas, B. Calahorra, D. De Las Heras, et al., "Terlipressin Therapy with and without Albumin for Patients with Hepatorenal Syndrome: Results of a Prospective, Nonrandomized Study," Hepatology, Vol. 36, No. 4, 2002, pp. 941-941. doi:10.1053/jhep.2002.35819

[16] M. Guevera, P. Gines, G. Fernandez-Esparrach, P. Sort, J. M. Salmero, W. Jimenez, et al., "Reversibility of Hepatorenal Syndrome by Prolonged Administration of Ornipressin and Plasma Volume Expansion,” Hepatology, Vol. 27, No. 1, 1998, pp. 35-41. doi:10.1002/hep.510270107

[17] V. Gulberg, M. Blizer and A. L. Gerbes, "Long-Term Therapy and Retreatment of Hepatorenal Syndrome Type 1 with Ornipressin and Dopamine,” Hepatology, Vol. 30, No. 4, 1999, pp. 870-875. doi:10.1002/hep.510300430

[18] T. H. Kiser, D. N. Fish, M. D. Obritsch, R. Jung, R. MacLaren and C. R. Rarikh, "Vasopressin, Not Octreotide, May Be Beneficial in the Treatment of Hepatorenal Syndrome: A Retrospective Study," Nephrology Dialysis Transplantation, Vol. 20, No. 9, 2005, pp.1813-1820. doi:10.1093/ndt/gfh930 